\title{
Evaluation of bacterial contamination in raw milk, ultra-high temperature milk and infant formula using single molecule, real-time sequencing technology
}

\author{
Qiangchuan Hou, ${ }^{1}$ Haiyan Xu, ${ }^{1}$ Yi Zheng, Xiaoxia Xi, Lai-Yu Kwok, Zhihong Sun, Heping Zhang, \\ and Wenyi Zhang ${ }^{2}$ \\ Key Laboratory of Dairy Biotechnology and Engineering, Ministry of Education, China, Inner Mongolia Agricultural University, Hohhot, \\ Inner Mongolia 010018, China
}

\begin{abstract}
The Pacific Biosciences (Menlo Park, CA) single molecule, real-time sequencing technology (SMRT) was reported to have some advantages in analyzing the bacterial profile of environmental samples. In this study, the presence of bacterial contaminants in raw milk, UHT milk, and infant formula was determined by SMRT sequencing of the full length $16 \mathrm{~S}$ rRNA gene. The bacterial profiles obtained at different taxonomic levels revealed clear differences in bacterial community structure across the 16 analyzed dairy samples. No indicative pathogenic bacteria were found in any of these tested samples. However, some of the detected bacterial species (e.g., Bacillus cereus, Enterococcus casseliflavus, and Enterococcus gallinarum) might potentially relate with product quality defects and bacterial antibiotic gene transfer. Although only a limited number of dairy samples were analyzed here, our data have demonstrated for the first time the feasibility of using the SMRT sequencing platform in detecting bacterial contamination. Our paper also provides interesting reference information for future development of new precautionary strategies for controlling the dairy safety in large-scale industrialized production lines.
\end{abstract}

Key words: dairy products, single molecule, realtime sequencing technology sequencing, bacterial contamination

\section{INTRODUCTION}

Bacterial contamination of dairy products is a great concern throughout the world, as the dairy production and consumption have been expanding extensively during the last decade; intense growth in the dairy indus-

Received May 29, 2015.

Accepted July 28, 2015.

${ }^{1}$ These authors contributed equally to this work.

${ }^{2}$ Corresponding author: zhangwenyizi@163.com try is anticipated to continue into the future (Fuller et al., 2007). Raw milk, UHT milk, and infant formula are the main types of dairy products consumed by adults and infants. These dairy products are known to contain rich nutrient contents, including carbohydrates, proteins, and minerals, which may promote the growth of microbes as well as some food-borne pathogens (Remenant et al., 2015). The consumption of pathogencontaining products may cause illnesses ranging from upset stomach to more serious symptoms (e.g., diarrhea, fever, vomiting, and so on; Ahmed et al., 2014). The occurrence of other types of bacteria may potentially affect the product nutritional and sensory quality properties and in turn result in significant economic losses (Janštová et al., 2006). Thus, developing effective and accurate methods of assessing microbial food contamination is of the utmost importance.

The traditional way of detecting bacterial contamination in dairy products relies on the use of culturebased methods in combination with biochemical tests (de Boer and Beumer, 1999). The process of sample analysis is time-consuming, not easy to handle, and the results can be ambiguous due to the variable biochemical phenotypes of microbes. These factors have prompted development of reliable and rapid methods for identification of microbes present in dairy products. Several studies have been performed by incorporating various molecular techniques, such as pulsed-field gel electrophoresis, real-time PCR, and microarray, to investigate the prevalence of contaminated bacteria and the level of the contamination in dairy products (Kim et al., 2011; Barancelli et al., 2014; Wareth et al., 2014). Whereas some improvements have been shown using these molecular-based detection techniques, one common limitation shared by these methodologies is the failure in providing an overall microbial profile in the samples, as most of these approaches require the detection of specific target microorganisms. The complete microbial profile offers an objective evaluation on the sample microbial quality and quantifies the contamination level, if any. 
The Pacific Biosciences (PacBio; Menlo Park, CA) single molecule, real-time sequencing technology (SMRT) was reported to have some advantages in analyzing the bacterial profiles of environmental samples based on the full-length 16S rRNA gene (Amir et al., 2013; Zhang et al., 2015). Thus, the present study aimed to apply such technology in assessing bacterial contamination of dairy products, including raw milk, UHT milk, and infant formula. Our study has demonstrated, for the first time, the feasibility of using the SMRT sequencing system in detecting the bacterial contamination in dairy samples, which would be of interest to the food industry for effective monitoring of microbial food quality and safety during production.

\section{MATERIALS AND METHODS}

\section{Sample Collection}

A total of 16 samples were collected, including 2 raw milk samples from a local farm, 4 UHT milk samples, and 10 infant formula samples from the supermarkets. Raw milk samples were collected aseptically and all samples were kept in ice boxes during transportation. The sample and sequence information are described in Table 1.

\section{DNA Extraction}

The DNA was extracted using the OMEGA DNA isolation kit (D5625-01, Omega, Norcross, GA) following the manufacturer's instructions. The quality of extracted DNA was checked by $1 \%$ agarose gel electrophoresis and spectrophotometry (optical density at
260/280 nm ratio). All extracted DNA samples were stored at $-20^{\circ} \mathrm{C}$ for further analysis.

\section{PCR Amplification}

The bacterial 16S rRNA was amplified by PCR for barcoded SMRT sequencing. It was amplified using the forward 27F (5'-GAGAGTTTGATCCTGGCTCAG-3') and the reverse 1541R (5'- AAGGAGGTGATCCAGCCGCA-3') primers. These primers contained a set of 16-nucleotide barcodes. The PCR amplifications of the $16 \mathrm{~S}$ rRNA regions were performed as described previously (Liu et al., 2015). The PCR program was $95^{\circ} \mathrm{C}$ for $4 \mathrm{~min}, 30$ cycles of $95^{\circ} \mathrm{C}$ for $60 \mathrm{~s}, 60^{\circ} \mathrm{C}$ for $45 \mathrm{~s}$, and $72^{\circ} \mathrm{C}$ for $60 \mathrm{~s}$ with a final extension of $72^{\circ} \mathrm{C}$ for $7 \mathrm{~min}$. The amplicons were sequenced using $\mathrm{P} 6-\mathrm{C} 4$ chemistry on a PacBio RS II instrument (Pacific Biosciences). The quality control for PCR amplifications and sequence preprocessing was performed as described previously (Mosher et al., 2013).

\section{Data Analysis}

Raw data processing was carried out using the protocol RS_ReadsOfinsert.1 available in SMRT Portal version 2.7 (PacBio). Filtering parameters, including minimum full passes, minimum predicted accuracy, minimum reads lengths of inserts, and maximum reads lengths, were set up with values 5, 90, 1,400, and 1,800 , respectively. The extraction of high-quality sequences was first performed with the QIIME package (Quantitative Insights In to Microbial Ecology; version 1.7; Caporaso et al., 2010b); PyNAST and UCLUST

Table 1. General information of sequence and diversity

\begin{tabular}{|c|c|c|c|c|c|c|c|}
\hline $\begin{array}{l}\text { Sample } \\
\text { no. }\end{array}$ & Type & $\begin{array}{l}\text { Number } \\
\text { of reads }\end{array}$ & $\begin{array}{c}\text { Number } \\
\text { of operational } \\
\text { taxonomic units }\end{array}$ & $\begin{array}{l}\text { Shannon } \\
\text { index }\end{array}$ & $\begin{array}{l}\text { Simpson } \\
\text { index }\end{array}$ & $\begin{array}{l}\text { Chaol } \\
\text { index }\end{array}$ & $\begin{array}{c}\text { Observed } \\
\text { species index }\end{array}$ \\
\hline 1 & Raw milk & 571 & 387 & 7.555 & 0.975 & $5,222.045$ & 350.816 \\
\hline 2 & Raw milk & 1,366 & 950 & 7.854 & 0.982 & $5,125.278$ & 379.756 \\
\hline 3 & UHT milk & 1,688 & 339 & 5.898 & 0.968 & 507.428 & 146.498 \\
\hline 4 & UHT milk & 1,294 & 324 & 5.997 & 0.949 & 463.753 & 177.47 \\
\hline 5 & UHT milk & 1,192 & 834 & 7.815 & 0.979 & $4,964.68$ & 379.198 \\
\hline 6 & UHT milk & 2,199 & 1,328 & 7.513 & 0.97 & $3,861.252$ & 350.416 \\
\hline 7 & Infant formula & 872 & 408 & 7.025 & 0.98 & $1,487.565$ & 263.488 \\
\hline 8 & Infant formula & 916 & 430 & 7.14 & 0.983 & $1,608.073$ & 266.288 \\
\hline 9 & Infant formula & 1,513 & 1,045 & 7.874 & 0.981 & $4,648.798$ & 383.314 \\
\hline 10 & Infant formula & 2,029 & 815 & 6.945 & 0.977 & $1,516.492$ & 259.276 \\
\hline 11 & Infant formula & 3,126 & 796 & 6.636 & 0.962 & $1,628.741$ & 253.016 \\
\hline 12 & Infant formula & 2,432 & 815 & 6.315 & 0.944 & $1,191.263$ & 228.288 \\
\hline 13 & Infant formula & 922 & 630 & 7.715 & 0.978 & $4,061.203$ & 365.938 \\
\hline 14 & Infant formula & 1,192 & 741 & 7.728 & 0.987 & $3,685.872$ & 345.208 \\
\hline 15 & Infant formula & 3,531 & 1,280 & 6.779 & 0.972 & $1,622.137$ & 248.942 \\
\hline 16 & Infant formula & 2,133 & 783 & 6.732 & 0.974 & $1,365.619$ & 239.074 \\
\hline
\end{tabular}


were then applied to align the extracted high-quality sequences under $100 \%$ clustering of sequence identity to obtain representative sequences (Caporaso et al., 2010a; Edgar, 2010). The unique sequence set was classified into operational taxonomic units (OTU) under the threshold of $99 \%$ identity using UCLUST after the selection of the representative sequences (Lozupone and Knight, 2005). The taxonomy of each OTU representative sequence was assigned using the Ribosomal Database Project II database that classified at a minimum bootstrap threshold of $80 \%$ (Cole et al., 2007). A de novo taxonomic tree was constructed employing a representative OTU set in FastTree for downstream analysis (Price et al., 2009), including the $\beta$ diversity calculation. The Shannon-Wiener, Simpson's diversity, Chao1, and rarefaction estimators were calculated to evaluate the $\alpha$ diversity. UniFrac distance was based on the phylogenetic tree (Lozupone and Knight, 2005). Both weighted and unweighted calculations were performed for the principal coordinate analysis. The graph presentations were generated by the $\mathrm{R}$ package version 3.1.2 (https://www.r-project.org/) and the Origin software version 8.5 (OriginLab Corporation, Hampton, MA).

\section{Nucleotide Sequence Accession Numbers}

The sequence data reported in this study have been deposited in the MG-RAST database (Accession No. 4633130.3-4633145.3; http://metagenomics.anl.gov/).

\section{RESULTS}

\section{Sequence Abundance and Diversity}

To obtain an accurate bacterial profile of the dairy products, SMRT sequencing of the full-length $16 \mathrm{~S}$ rRNA gene was performed. A total of 26,976 raw reads were generated from 16 dairy product samples, with an average of 1,686 reads for each sample. By calculating the Shannon index, Simpson index, Chao1 index, and observed species index (Table 1), it is clear that most samples had a high level of bacterial biodiversity. In particular, one of the infant formula samples (sample no. 9) was found to have the highest diversity, with a Shannon index value of 7.874 . The Shannon-Wiener diversity curves showed that the sequence depth was adequate for all samples (Figure 1). Although new phylogroups are likely to be discovered along with an increase in sequencing depth, the data presented here show that most of the sample bacterial diversity has been captured.

\section{Bacterial Composition in Raw Milk, UHT Milk, and Infant Formula}

The sequences generated by the SMRT platform were identified to the phylum, genus, and species levels to enable an in-depth analysis of sample bacterial communities. Generally, the dairy samples displayed an unbalanced bacterial composition distribution, with highly variable bacterial relative abundances differing between samples.

Using the Ribosomal Database Project classifier, more than 19 phyla were identified from all samples, 5 of them had an average relative abundance of over 1\%, namely Firmicutes, Proteobacteria, Actinobacteria, Deinococcus-Thermus, and Cyanobacteria. Firmicutes appeared to be the most prevalent phylum in all samples, whereas the latter 6 phyla together only comprised a low proportion (Figure 2). At the genus level, the average relative abundances of Enterococcus, Lactococcus, Solibacillus, Bacillus, Lactobacillus, Streptococcus, Sporosarcina, Pseudomonas, Propionibacterium, Thermus, and Acinetobacter were found to be larger than 1\% (Figure 3). In particular, Enterococcus and Lactococcus were the 2 most abundant genera found in the dairy products. The proportion of Enterococcus in infant formula samples ranged from 1.5 to $80 \%$. Two members of this genus, Enterococcus casseliflavus $(14.9 \%)$ and Enterococcus gallinarum (9.7\%), were among the most prevalent in milk powder samples (Figure 4). Reads belonging to the species Thermus thermophilus, Streptococcus salivarius, Sporosarcina newyorkensis, and Bacillus cereus were present in all samples with similar percentages. Besides, another 6 (including Lactococcus piscium, Solibacillus silvestris, Lactococcus lactis, Lactobacillus delbrueckii, Enterococcus durans, and Propionibacterium acnes) out of 334 identified species were detected in the samples having percentages higher than $1 \%$.

\section{Comparison of the Bacterial Profiles Between Different Dairy Products}

To evaluate the structural differences of the bacterial profile across different dairy products, principal coordinate analyses based on the weighted and unweighted UniFrac distances were performed. Scores plots generated with principal components 1 and 2 displayed no clear clustering pattern based on the different dairy sample types (Supplementary Figure S1; http://dx.doi. org/10.3168/jds.2015-9886). However, distinct clusters were identified by plotting with principal components 3 and 4 (Figure 5), respectively, accounting for 24.91 and $14.36 \%$ of the total variance. These results suggest the 


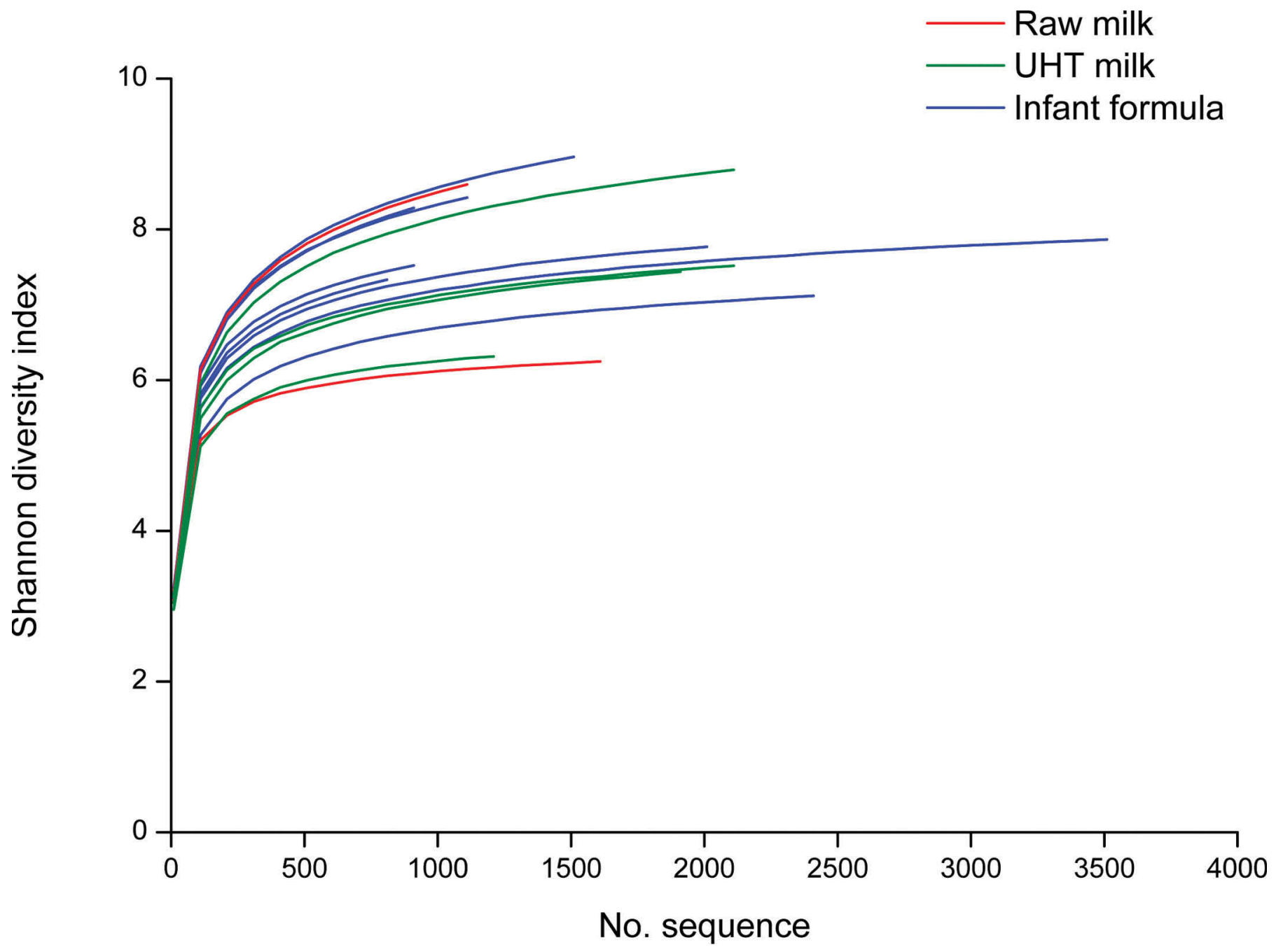

Figure 1. Shannon diversity index curves that estimate the microbial diversity of the dairy products.

existence of some representative bacterial components in each sample type.

\section{DISCUSSION}

Dairy products are valuable food resources that can meet the growing nutritional demand of the large population in the world. Bacterial contamination in these products poses a serious public health threat and compromises food quality. Thus, it is crucial to develop accurate and rapid methods for evaluating bacterial contamination in the dairy products. Even though multiple molecular detection techniques have largely improved the traditional cultivation- and biochemicalbased detection approaches, currently available methods for assessing dairy food contamination appear to be unsatisfactory.
Our study reports for the first time the feasibility of using the latest PacBio SMRT sequencing technology to describe the bacterial contamination profile of dairy products based on the full-length 16S rRNA gene. The PacBio SMRT technology is advantageous over other sequencing approaches as it has previously been shown to offer a higher taxonomical resolution in profiling the bacterial communities in the environmental samples due to its high capacity in producing long sequence reads (Schloss et al., 2015). For the last few years, data on bacterial profiling were generated largely by the 454 (Roche, Basel, Switzerland) and Illumina (San Diego, CA) MiSeq platforms; both platforms generate high-quality, but short sequence reads that preclude from accurate assignment of DNA sequences to the precision of species or even limit the classification to the genus level (Amir et al., 2013). By employing the 
SMRT sequencing technology, clear bacterial structural differences were revealed across 16 samples of raw milk, UHT milk, and infant formula.

Owing to the mild taste, convenience, low cost, and high nutritional quality, popularity of raw milk is growing among adults (Kaylegian et al., 2008); however, the rising trend of raw milk consumption has been accompanied by food poisoning outbreaks (Oliver et al., 2009). In Europe and the United States, thermophilic
Campylobacter spp., shigatoxic Escherichia coli, Salmonella spp., and Staphylococcus aureus are the 4 main pathogenic bacteria frequently associated with milkborne outbreaks (Ruusunen et al., 2013). Moreover, Listeria monocytogenes and Yersinia enterocolitica have been reported in raw cow milk sampled from Finland (Ruusunen et al., 2013). These pathogenic bacteria have not been detected in any of our samples. Instead, the 2 species, L. piscium and S. silvestris, were found

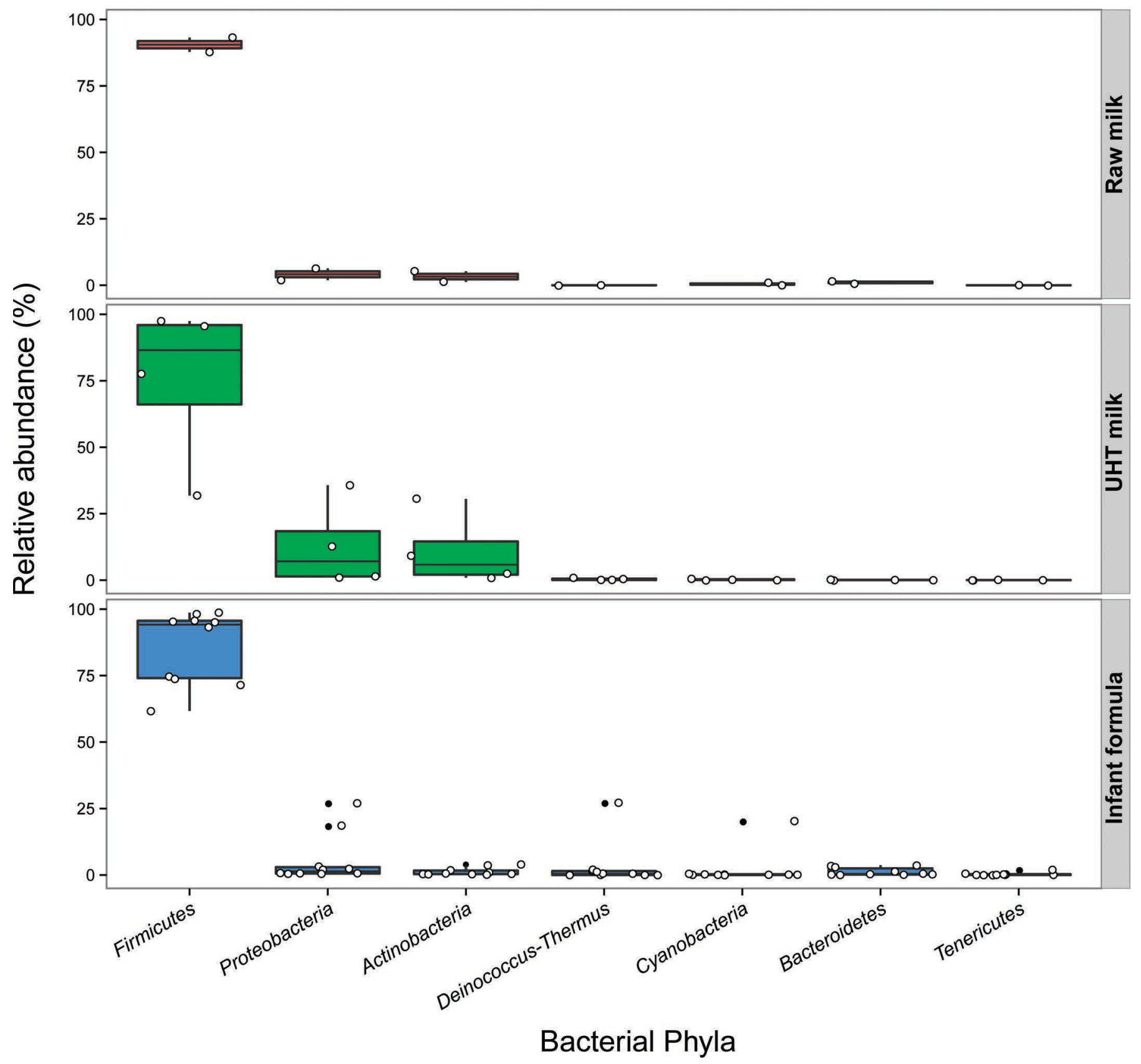

Figure 2. Boxplots of the relative abundance of bacteria detected in the dairy products at the phylum level. Filled dots represent outliers; open dots represent specific samples. 
to dominate the microflora in the sampled raw milk. In fact, milk collected from the cow udder normally has a low bacterial load, and the dominance of these 2 species is likely related to the contamination during milking or other postmilking processing procedures.

Ultra-high temperature milk is another popular dairy product consumed by adults. The high temperature treatment during UHT milk production is a straightforward processing step that helps to kill the bacteria present in the raw milk and, thus, extends the shelf life of the final products; however, such processes does not guarantee that the milk is totally free from bacterial contamination. Both thermophiles and mesophiles are prevalent in UHT milk, as detected by culturedependent methods (Abd et al., 2014). Thermophilic bacteria (e.g., members of the Bacillus genus, as they are named) are able to grow at high temperatures, accounting for the majority of the contamination events

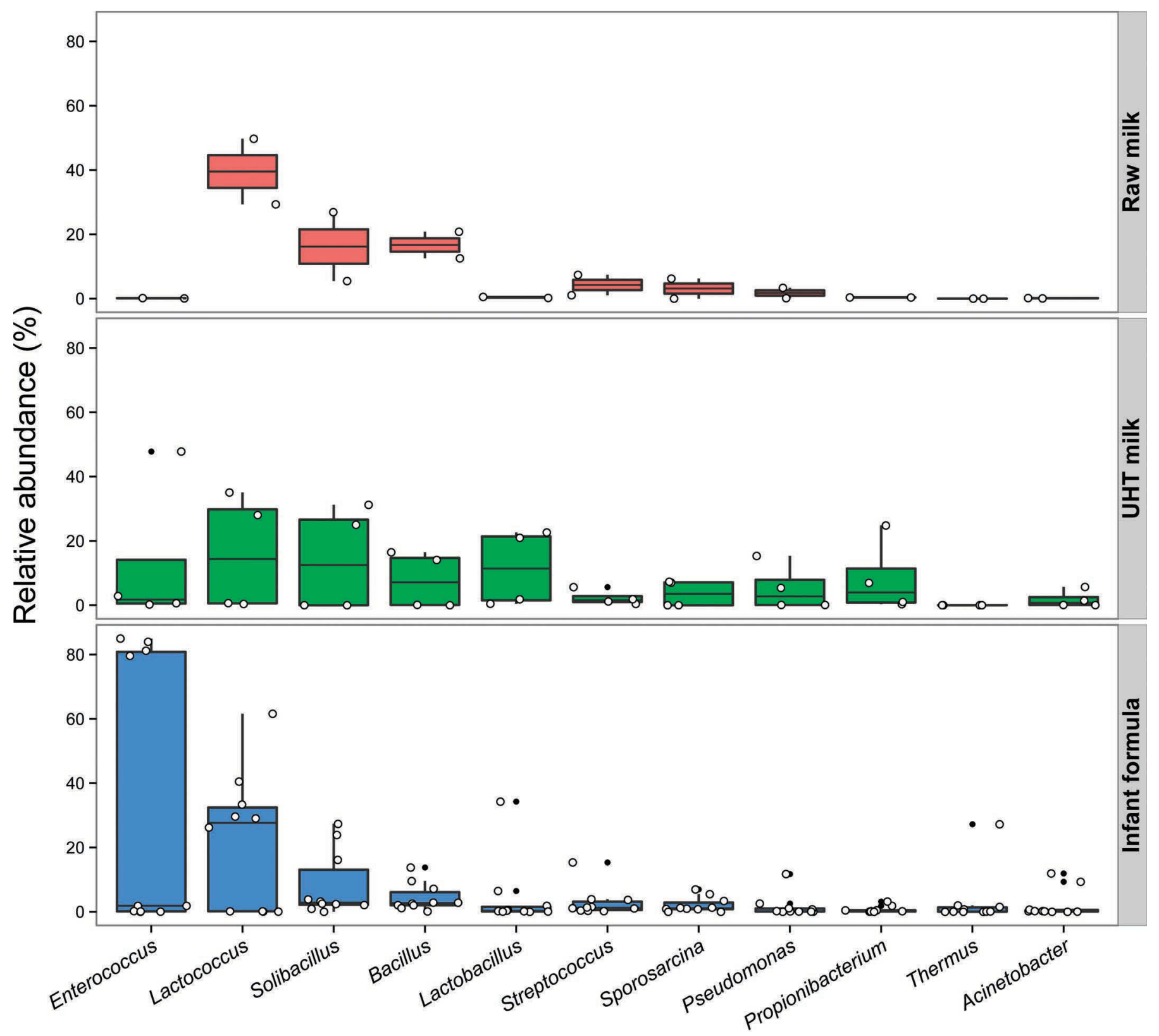

Bacterial Genus

Figure 3. Boxplots of the relative abundance of bacteria detected in the dairy products at the genus level. Filled dots represent outliers; open dots represent specific samples. 
(Al-Shamary and Abdalali, 2011). Even though most of these bacteria seldom cause life- or health-threatening concerns, they affect the food product quality adversely by causing defects, such as sweet curdling and off flavors (Stenfors Arnesen et al., 2008). In the present study, B. cereus, potentially both a food spoiler and a toxin-producer (Scheldeman et al., 2006), was detected at a relatively low level among various bacteria, which raises alarm over the quality of the sampled UHT milks.
Among the 3 tested product types, infant formula has received the greatest attention in China, probably because of the increase in public awareness of food safety and the high vulnerability of infants to food-borne illness. Similar to the raw milk, certain pathogenic contaminant bacteria in infant formula are causative agents of human infections (Wang et al., 2009; Jongenburger et al., 2011). Besides, the presence of antibioticresistant species in infant formula has aroused serious

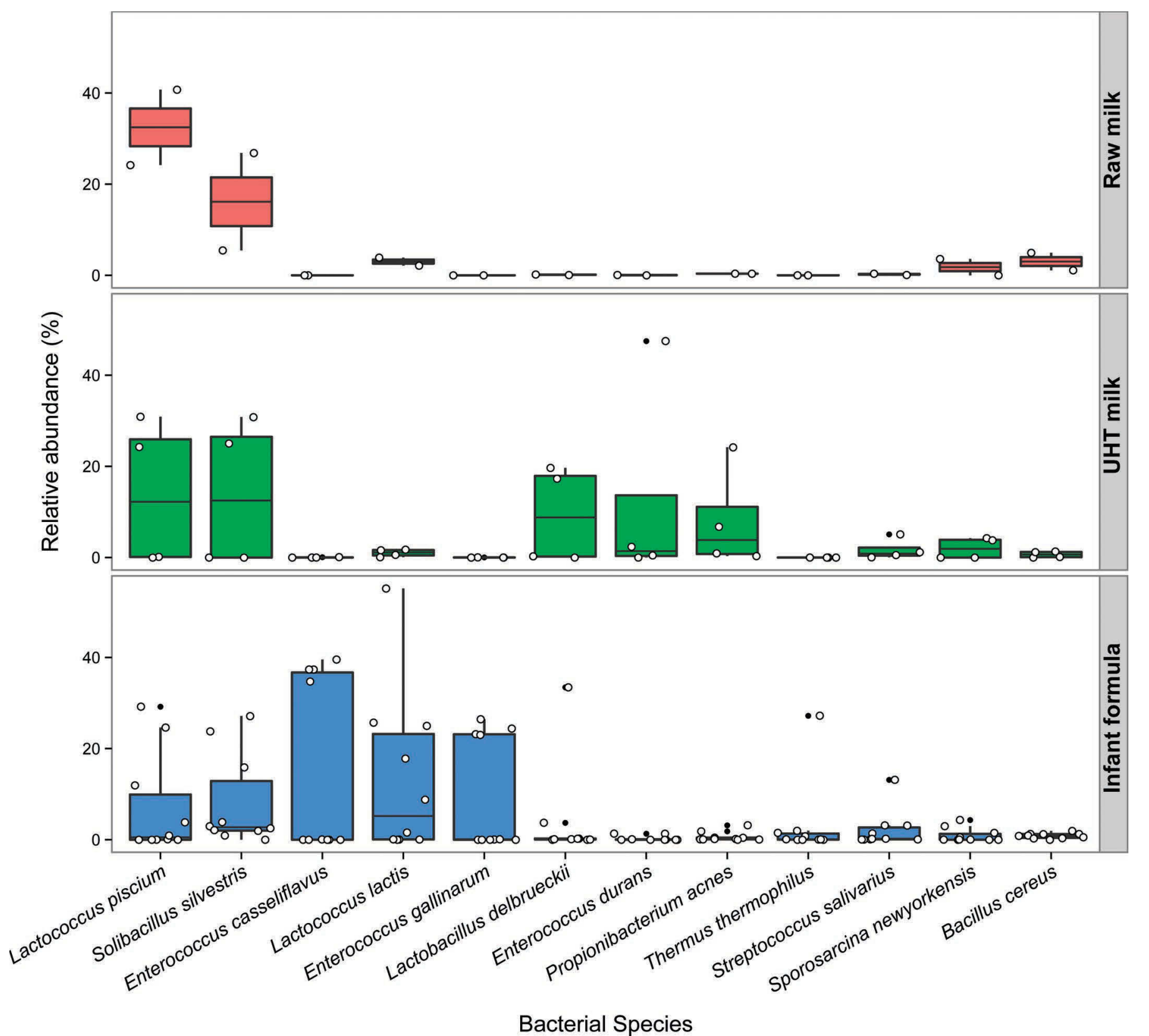

Figure 4. Boxplots of the relative abundance of bacteria detected in the dairy products at the species level. Filled dots represent outliers; open dots represent specific samples. 
concerns. It has been suggested that the wide adoption of antibiotic treatment against cow diseases had led to multiple antibiotic-resistant bacteria (Johnston et al., 1983). These bacteria can transfer antibiotic-resistant genes to originally sensitive hosts and render them antibiotic resistant via conjugation (Alm et al., 2014). The problem of antibiotic resistance has escalated to become a major clinical and public health crisis, as some potent antibiotics are losing their effectiveness at an alarming rate. As some antibiotic-resistant Entero-
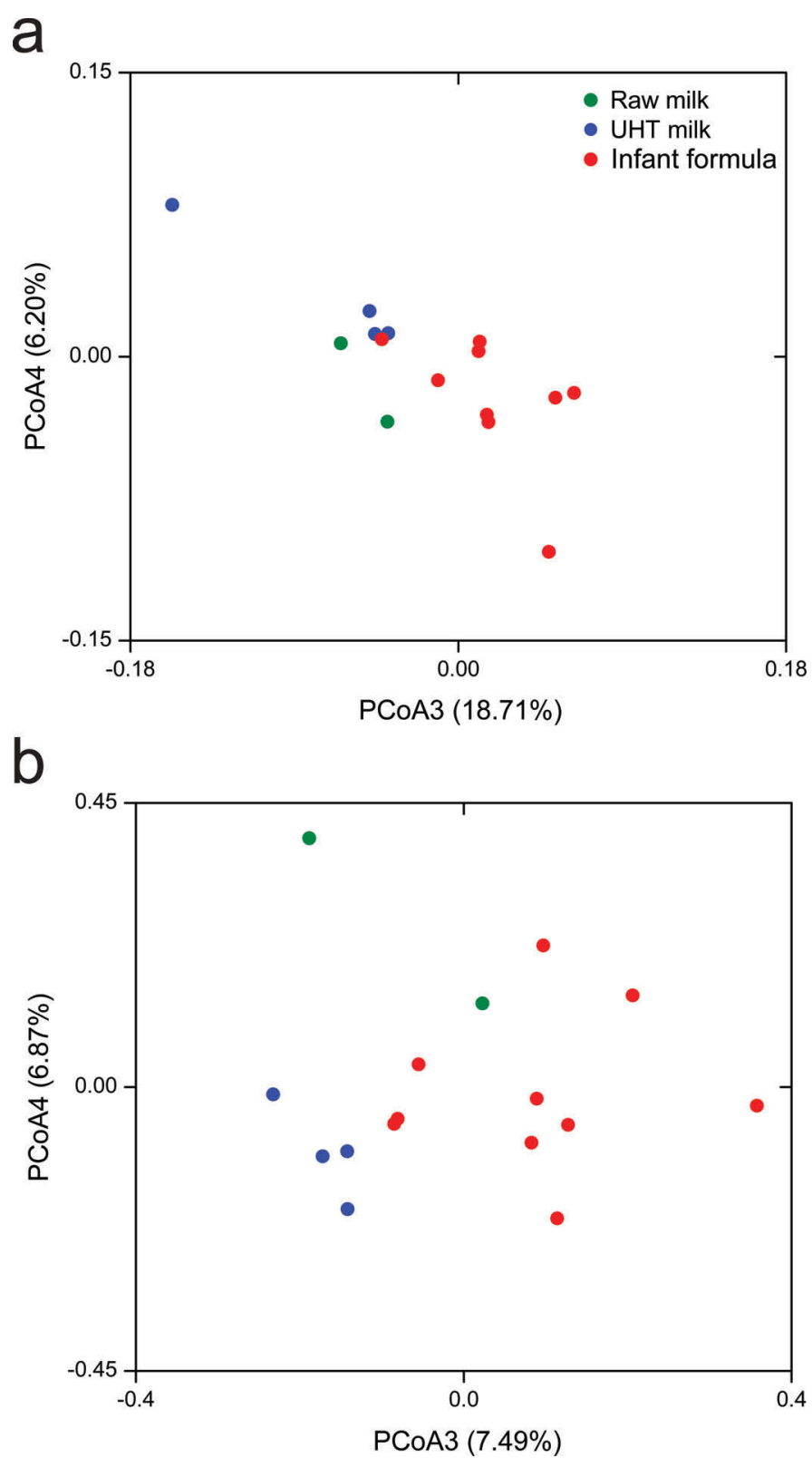

Figure 5. UniFrac weighted (a) and unweighted (b) principal coordinate analysis ( $\mathrm{PCoA})$ scores plot based on principal components 3 and 4 . coccus strains have been reported (Jahne et al., 2015), the high incidences of the species, E. casseliflavus and E. gallinarum, present in the infant formula should be carefully tracked and further characterized, even though these species rarely cause human infections.

\section{CONCLUSIONS}

In the present study, microbial contamination of dairy products was detected using the PacBio SMRT sequencing system by producing long sequence reads. Our results have preliminarily demonstrated that this sequencing technique can provide an accurate taxonomic classification to the precision of the genus and species levels, and thus largely increase our capacity in discriminating between bacterial contaminants. However, due to the low number of samples used in this study, further in-depth work will be needed to establish a more complete set of guidelines for its future application in the dairy quality control during industrial production.

\section{ACKNOWLEDGMENTS}

This research was supported by the National Natural Science Foundation of China (Beijing; Grant No. 31430066 and 31201396), Hi-Tech Research and Development Program of China (Beijing; 863 Planning, Grant No. 2011AA100901 and 2011AA100902), International S\&T Cooperation Program of China (ISTCP, Beijing; Grant No.2014DFR31150), the China Agriculture Research System (Beijing; Grant No. CARS-37), and the Major State Basic Research Development Program of China (Beijing; 973 Program, 2012CB720802).

\section{REFERENCES}

Abd, A. A. H., N. I. AbdulA'Al, and A. S. Abood. 2014. Prevalence of thermophiles and mesophiles in raw and UHT milk. Int. J. Anim. Vet. Adv. 6:24-27.

Ahmed, M. M. M., E. E. Hafez, M. M. Hassan, H. A. Abdelrrassoul, and Y. M. Mabrouk. 2014. Detection of infant formula contamination by microorganisms. World Appl. Sci. J. 30:93-98.

Al-Shamary, A. H. A., and N. I. Abdalali. 2011. Detection of microbial load in imported UHT milk in Baghdad. Al-Anbar J. Vet. Sci. 4:103-107.

Alm, E. W., D. Zimbler, E. Callahan, and E. Plomaritis. 2014. Patterns and persistence of antibiotic resistance in faecal indicator bacteria from freshwater recreational beaches. J. Appl. Microbiol. 117:273-285.

Amir, A., A. Zeisel, O. Zuk, M. Elgart, S. Stern, O. Shamir, P. J. Turnbaugh, Y. Soen, and N. Shental. 2013. High-resolution microbial community reconstruction by integrating short reads from multiple 16S rRNA regions. Nucleic Acids Res. 41:e205.

Barancelli, G. V., T. M. Camargo, N. G. Gagliardi, E. Porto, R. A Souza, F. Campioni, J. P. Falcao, E. Hofer, A. G. Cruz, and C. A. Oliveira. 2014. Pulsed-field gel electrophoresis characterization of Listeria monocytogenes isolates from cheese manufacturing plants in Sao Paulo, Brazil. Int. J. Food Microbiol. 173:21-29. 
Caporaso, J. G., K. Bittinger, F. D. Bushman, T. Z. DeSantis, G. L. Andersen, and R. Knight. 2010a. PyNAST: A flexible tool for aligning sequences to a template alignment. Bioinformatics $26: 266-267$.

Caporaso, J. G., J. Kuczynski, J. Stombaugh, K. Bittinger, F. D Bushman, E. K. Costello, N. Fierer, A. G. Pena, J. K. Goodrich, J. I. Gordon, G. A. Huttley, S. T. Kelley, D. Knights, J. E. Koenig, R. E. Ley, C. A. Lozupone, D. McDonald, B. D. Muegge, M. Pirrung, J. Reeder, J. R. Sevinsky, P. J. Turnbaugh, W. A. Walters, J. Widmann, T. Yatsunenko, J. Zaneveld, and R. Knight. 2010b. QIIME allows analysis of high-throughput community sequencing data. Nat. Methods 7:335-336.

Cole, J. R., B. Chai, R. J. Farris, Q. Wang, A. S. Kulam-Syed-Mohideen, D. M. McGarrell, A. M. Bandela, E. Cardenas, G. M. Garrity, and J. M. Tiedje. 2007. The ribosomal database project (RDP-II): Introducing myRDP space and quality controlled public data. Nucleic Acids Res. 35:D169-D172.

de Boer, E., and R. R. Beumer. 1999. Methodology for detection and typing of foodborne microorganisms. Int. J. Food Microbiol. 50:119-130.

Edgar, R. C. 2010. Search and clustering orders of magnitude faster than BLAST. Bioinformatics 26:2460-2461.

Fuller, F., J. Beghin, and S. Rozelle. 2007. Consumption of dairy products in urban China: Results from Beijing, Shanghai and Guangzhou. Aust. J. Agric. Resour. Econ. 51:459-474.

Jahne, M. A., S. W. Rogers, I. P. Ramler, E. Holder, and G. Hayes. 2015. Hierarchal clustering yields insight into multidrug-resistant bacteria isolated from a cattle feedlot wastewater treatment system. Environ. Monit. Assess. 187:4168.

Janštová, B., M. Dračková, and L. Vorlová. 2006. Effect of Bacillus cereus enzymes on milk quality following ultra high temperature processing. Acta Vet. (Brno) 75:601-609.

Johnston, D. W., J. Bruce, and J. Hill. 1983. Incidence of antibioticresistant Escherichia coli in milk produced in the west of Scotland. J. Appl. Bacteriol. 54:77-83.

Jongenburger, I., M. W. Reij, E. P. Boer, L. G. Gorris, and M. H. Zwietering. 2011. Actual distribution of Cronobacter spp. in industrial batches of powdered infant formula and consequences for performance of sampling strategies. Int. J. Food Microbiol. 151:62-69.

Kaylegian, K. E., R. Moag, D. M. Galton, and K. J. Boor. 2008. Raw milk consumption beliefs and practices among New York State dairy producers. Food Prot. Trends 28:184-191.

Kim, S. A., S. W. Oh, Y. M. Lee, J. Y. Imm, I. G. Hwang, D. H. Kang, and M. S. Rhee. 2011. Microbial contamination of food products consumed by infants and babies in Korea. Lett. Appl. Microbiol. $53: 532-538$.

Liu, W., Y. Zheng, L. Y. Kwok, Z. H. Sun, J. C. Zhang, Z. Guo, Q. C. Hou, B. L. G. Menghe, and H. P. Zhang. 2015. High-throughput sequencing for the detection of the bacterial and fungal diversity in Mongolian naturally fermented cow's milk in Russia. BMC Microbiol. 15:45

Lozupone, C., and R. Knight. 2005. UniFrac: A new phylogenetic method for comparing microbial communities. Appl. Environ. Microbiol. 71:8228-8235.

Mosher, J. J., E. L. Bernberg, O. Shevchenko, J. Kan, and L. A. Kaplan. 2013. Efficacy of a 3rd generation high-throughput sequencing platform for analyses of $16 \mathrm{~S}$ rRNA genes from environmental samples. J. Microbiol. Methods 95:175-181.

Oliver, S. P., K. J. Boor, S. C. Murphy, and S. E. Murinda. 2009. Food safety hazards associated with consumption of raw milk. Foodborne Pathog. Dis. 6:793-806.

Price, M. N., P. S. Dehal, and A. P. Arkin. 2009. FastTree: Computing large minimum evolution trees with profiles instead of a distance matrix. Mol. Biol. Evol. 26:1641-1650.

Remenant, B., E. Jaffres, X. Dousset, M. F. Pilet, and M. Zagorec 2015. Bacterial spoilers of food: Behavior, fitness and functional properties. Food Microbiol. 45:45-53. http://dx.doi.org/10.1016/j fm.2014.03.009.

Ruusunen, M., M. Salonen, H. Pulkkinen, M. Huuskonen, S. Hellstrom, J. Revez, M. L. Hanninen, M. Fredriksson-Ahomaa, and M. Lindstrom. 2013. Pathogenic bacteria in Finnish bulk tank milk. Foodborne Pathog. Dis. 10:99-106.

Scheldeman, P., L. Herman, S. Foster, and M. Heyndrickx. 2006. Bacillus sporothermodurans and other highly heat-resistant spore formers in milk. J. Appl. Microbiol. 101:542-555.

Schloss, P. D., S. L. Westcott, M. L. Jenior, and S. K. Highlander. 2015. Sequencing 16S rRNA gene fragments using the PacBiol. SMRT DNA sequencing system. PeerJ http://dx.doi.org/10.7287/ peerj.preprints.778v1.

Stenfors Arnesen, L. P., A. Fagerlund, and P. E. Granum. 2008. From soil to gut: Bacillus cereus and its food poisoning toxins. FEMS Microbiol. Rev. 32:579-606.

Wang, M., B. Cao, Q. Gao, Y. Sun, P. Liu, L. Feng, and L. Wang. 2009. Detection of Enterobacter sakazakii and other pathogens associated with infant formula powder by use of a DNA microarray. J. Clin. Microbiol. 47:3178-3184.

Wareth, G., F. Melzer, M. C. Elschner, H. Neubauer, and U. Roesler. 2014. Detection of Brucella melitensis in bovine milk and milk products from apparently healthy animals in Egypt by real-time PCR. J. Infect. Dev. Ctries. 8:1339-1343.

Zhang, W., Z. Sun, B. Menghe, and H. Zhang. 2015. Short communication: Single molecule, real-time sequencing technology revealed species- and strain-specific methylation patterns of 2 Lactobacillus strains. J. Dairy Sci. 98:3020-3024. 